\title{
Leadership is associated with lower levels of stress
}

\author{
Gary D. Sherman ${ }^{a}$, Jooa J. Lee ${ }^{a}$, Amy J. C. Cuddy ${ }^{b}$, Jonathan Renshon', Christopher Oveis ${ }^{d}$, James J. Gross ${ }^{e}$, \\ and Jennifer S. Lerner ${ }^{\mathrm{a}, 1}$
}

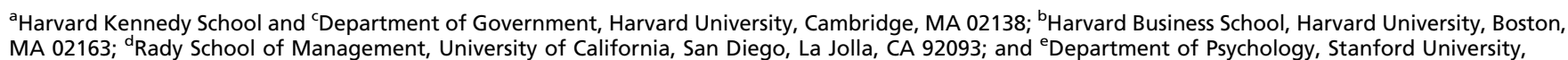
Stanford, CA 94305

Edited by Shelley E. Taylor, University of California, Los Angeles, CA, and approved August 24, 2012 (received for review May 2, 2012)

\begin{abstract}
As leaders ascend to more powerful positions in their groups, they face ever-increasing demands. As a result, there is a common perception that leaders have higher stress levels than nonleaders. However, if leaders also experience a heightened sense of controla psychological factor known to have powerful stress-buffering effects-leadership should be associated with reduced stress levels. Using unique samples of real leaders, including military officers and government officials, we found that, compared with nonleaders, leaders had lower levels of the stress hormone cortisol and lower reports of anxiety (study 1). In study 2, leaders holding more powerful positions exhibited lower cortisol levels and less anxiety than leaders holding less powerful positions, a relationship explained significantly by their greater sense of control. Altogether, these findings reveal a clear relationship between leadership and stress, with leadership level being inversely related to stress.
\end{abstract}

neuroendocrine | psychological resources | organizations | management | health

A s people ascend to positions of leadership, demands increase dramatically (1), but the number of hours in the day does not increase. Because stress results when demands exceed resources (2), leadership is often viewed as highly stressful. Reflecting this view, in a classic Harvard Business Review article (3), psychologist Harry Levinson noted that "managing others ... creates unending stress ... Today's managers face increasing time pressures with little respite" (ref. 3, p. 77). Not surprisingly, social scientists and practitioners have proposed and developed scores of tools to help leaders manage their stress, and leader stress management has become a vibrant industry.

This widespread view of leadership was reinforced by an oftencited study on stress in primates; rhesus monkeys that were endowed with the ability to control whether they received electric shocks developed more ulcers than those monkeys who passively received the shocks, thereby buttressing a portrait of leaders as suffering from "executive stress syndrome" (4). This finding, however, was later debunked (5), when it was discovered that the results were an artifact of the executive monkeys having been selected for their greater emotional reactivity rather than having been randomly assigned (6). Indeed, findings from diverse fields suggest a competing view of leadership-that leaders may be less stressed than nonleaders.

For example, the work by Sapolsky (7) found that, in nonhuman primate species, higher social rank is associated with lower cortisol, a stress hormone and primary output of the hypothalamicpituitary-adrenal axis. This relationship is especially apparent when the hierarchy is uncontested and harassment of subordinates is frequent $(8,9) .{ }^{*}$ One study, however, found that for baboons, the pattern did not hold at the very top of the hierarchy (11).

In further support, human studies have linked higher employment rank to better health (12) and higher socioeconomic status (SES; i.e., education and income) to better health (13) and lower evening cortisol levels (14) [the SES-cortisol findings are somewhat inconsistent and depend on time of day; for example, one study found that educational level was positively correlated with morning cortisol levels (i.e., the awakening response) but unrelated to evening levels (15)]. Building on this evidence, the present studies examine whether leaders and nonleaders differ in their stress levels, independent of differences in other facets of SES (e.g., education and income).

We propose that leaders experience less stress than nonleaders. We suspect that leaders have lower levels of stress because of the psychological resources that leadership affords. In particular, holding a leadership role boosts one's sense of control (16), a psychological resource known to have a stress-buffering effect (17). For example, possessing control over a stressor alters its physiological consequences (18), reducing the release of cortisol $(19,20)$. Similarly, individuals who believe that they have control over their lives tend to have lower cortisol levels (21). Most pertinent to the current investigation is research, based on the classic demand-control model (22), showing that the adverse health effects of job strain are buffered by having a sense of control in one's job $(23,24)$. Based on this previous research, we hypothesized that increases in leadership, by heightening one's sense of control, may buffer against stress.

Despite longstanding interest in this issue, the nature of the leadership-stress link among humans remains unresolved, in part because of the difficulty of obtaining a suitable sample of real leaders. In the present research, we assessed community members as well as government and military leaders enrolled in a unique executive education program at Harvard University. This program primarily enrolls managers and professionals working in the federal government and military (i.e., the public sector). As a result of our access to these individuals, we were able to recruit samples that included middle- to high-level government officials and military officers.

In two studies, we used these unique samples to test the relationship between leadership and stress in multiple ways using multiple indicators of stress. In each study, we assessed salivary cortisol and anxiety reports. These two indicators of stress provide two different windows into the stress response. In study 1 , we tested whether leaders and nonleaders differed in their levels of salivary cortisol and/or reports of anxiety. In study 2 , we tested for a potential dose-response relationship within leaders by examining whether higher-level leaders had lower cortisol levels and less anxiety than lower-level leaders. Additionally, we tested

Author contributions: J.R., C.O., J.J.G., and J.S.L. designed research; J.J.L., J.R., C.O., and J.S.L. performed research; G.D.S., J.J.L., J.J.G., and J.S.L. analyzed data; G.D.S., J.J.L., A.J.C.C., J.R., C.O., J.J.G., and J.S.L. contributed to theory development; and G.D.S., J.J.L., A.J.C.C., J.R., C.O., J.J.G., and J.S.L. wrote the paper.

The authors declare no conflict of interest.

This article is a PNAS Direct Submission.

See Commentary on page 17730.

${ }^{1}$ To whom correspondence should be addressed. E-mail: jennifer_lerner@harvard.edu.

This article contains supporting information online at www.pnas.org/lookup/suppl/doi:10. 1073/pnas.1207042109/-/DCSupplemental.

*Additionally, a recent study of rhesus macaques found that changes in social rank alter the expression of various genes, such as those genes that control immune functioning (10), providing a potential mechanism by which social rank could affect stress and health. The study, however, does not answer the question of whether the changes in gene expression that come with higher rank are associated with better or worse health (we thank an anonymous reviewer for pointing out this question). Future research is needed to verify the viability of this potential mechanism. 
whether the lower stress of high-level leaders could be explained by a greater sense of control.

\section{Study 1}

Overview. In study 1, we examined the leadership-stress relationship by testing whether leaders-those individuals who indicated that they were responsible for managing others-and nonleaders differed in their levels of salivary cortisol, a physiological indicator of stress, and/or anxiety reports.

Results and Discussion. Cortisol and anxiety reports were not related to each other $(r=0.06, P=0.34)$, consistent with research showing that psychological and physiological manifestations of stress are often loosely coupled (25). For example, one study found that individuals with generalized anxiety disorder differed from a control group in terms of both self-report symptoms (e.g., worry) and autonomic physiology (e.g., elevated heart rate) but that the two types of indicators were uncorrelated (26). Similarly, in the current study, salivary cortisol and anxiety reports may capture largely independent manifestations of the stress response. If so, they may both relate to leadership, despite being uncorrelated.

A model predicting cortisol from leadership (dummy-coded) revealed that leaders had significantly lower cortisol than nonleaders $(\beta=-0.26, P<0.001)$. The average leader's cortisol level was 0.54 SDs lower than the average nonleader (Fig. 1). Analysis of anxiety reports provided convergent evidence that leaders experienced less stress: leaders had lower levels of anxiety than nonleaders $(\beta=-0.23, P<0.001)$ (Fig. 2). Leadership remained a significant predictor of both cortisol and anxiety reports when controlling for demographic variables (sex, age, education, and income) and mood.

Research on nonhuman primates suggests that the leadershipstress relationship may depend on whether the social hierarchy is uncontested $(8,27)$, raising the possibility that the observed relationship between leadership and stress in human leaders may depend on leaders occupying relatively stable positions. The majority of the leaders in the current sample came from an executive education program that targets individuals from organizations that are highly committed to their advancement. Moreover, organizations currently experiencing substantial instability or change would be unlikely to send one of their employees to such a program. As a result, the leaders in the sample, on average, presumably enjoyed a high level of stability and security, making the current study most comparable with nonhuman primate studies on stable, uncontested hierarchies. The lack of any serious instability in the leader group prevents us from thoroughly testing the potential moderating role of stability in the observed leadership-stress relationship. Nevertheless, participants (leaders and nonleaders) were asked to indicate the length of time

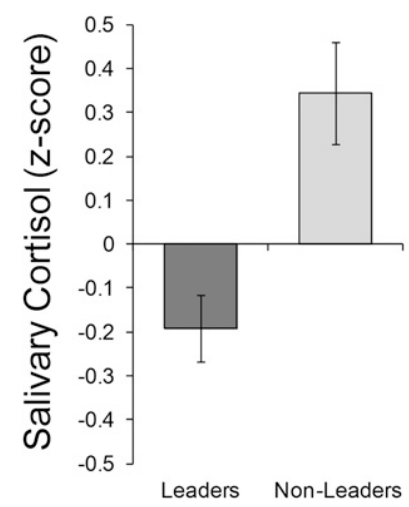

Fig. 1. Cortisol as a function of leadership (study 1). Error bars represent \pm 1 SEM.

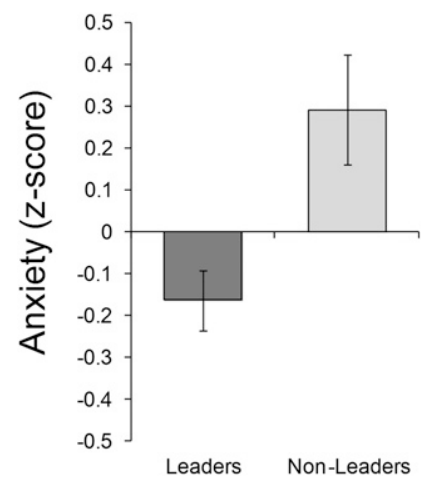

Fig. 2. Anxiety reports as a function of leadership (study 1). Error bars represent \pm 1 SEM.

that they had occupied their current position (i.e., tenure). If individuals develop a sense of job security over time, with a longer tenure providing a greater sense of stability, then tenure may serve as a rough proxy for the extent to which one's status as a leader (or nonleader) is firmly entrenched. However, neither of the observed relationships - between leadership and cortisol and between leadership and anxiety—was moderated by tenure $(t$ values $<1){ }^{\dagger}$

\section{Study 2}

Overview. A leadership role may confer lower stress by elevating one's sense of control. In study 2 , we extended our findings by testing the prediction that the relationship between leadership and stress is mediated by differences in the sense of control. In a second group, consisting exclusively of leaders, we examined links among leadership level, sense of control, and our two indicators of stress (cortisol and anxiety). Leaders can vary in their rank or power in a variety of ways. A high-ranking leader might be responsible for personally managing a large number of individuals, might have many subordinates (including those individuals who do not report directly to him or her), or might be given great authority and autonomy to make decisions concerning his or her subordinates. To capture the different forms of leadership, we assessed leadership level in each of these ways - total number of subordinates, number of direct reports, and authority. Additionally, we used these different indicators to test whether certain leadership dimensions display a particularly strong relation to sense of control and consequently, stress.

Results and Discussion. As in study 1 , cortisol and anxiety reports were uncorrelated $(r=0.06, P=0.62)$. As predicted, higher leadership level, which we indexed with a composite of our three measures of leadership (total number of subordinates, number of direct reports, and authority) was associated with lower cortisol $(\beta=-0.36, P=0.001)$ and lower anxiety $(\beta=-0.23, P=0.03)$. Next, to explore whether these two leadership-stress relationships could be explained by sense of control, we tested mediation models (28). The inverse relationship between leadership level and cortisol $(\beta=-0.36, P=0.001)$ was significantly mediated by sense of control [95\% confidence interval (CI) for indirect effect $=-0.28$ to -0.004 ]; higher leadership level predicted greater sense of control $(\beta=0.36, P<0.001)$, which in turn, predicted lower cortisol $(\beta=-0.20, P=0.09)$ (Fig. $3 A)$. The same pattern emerged for anxiety reports. The inverse relation-

${ }^{\dagger}$ Because the moderating effect of tenure may be nonlinear (e.g., the leadership-stress relationship may emerge after stability reaches a critical threshold), when testing moderation by tenure, we tested for both linear and nonlinear moderation. We tested in a regression model that included both the linear and quadratic terms of the tenure variable and their interaction with leadership. Repeating these analyses in study 2 also revealed no evidence of moderation by tenure ( $t$ values $<1.21, P$ values $>0.23$ ). 


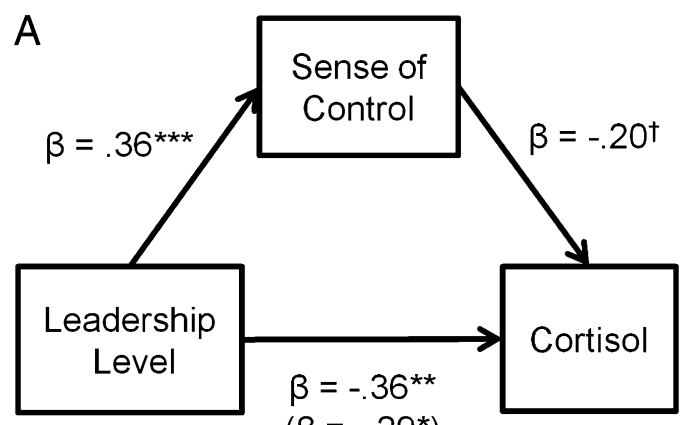

$\left(\beta=-.29^{*}\right)$

$95 \%$ confidence interval for indirect effect: -.28 to -.004

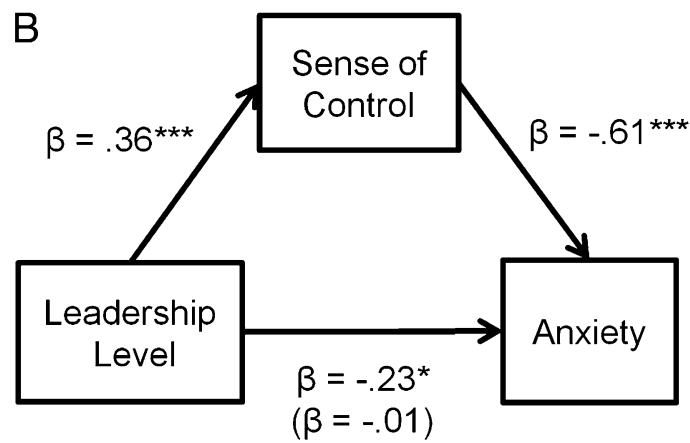

$95 \%$ confidence interval for indirect effect: -.52 to -.12

${ }^{\dagger} p<.10^{*} p<.05^{* *} p<.01{ }^{* * *} p<.001$

Fig. 3. For leaders (study 2), mediation models depicting relationship among leadership level, sense of control, and the two indicators of stress. (A) Sense of control as a mediator of the leadership-cortisol relationship. (B) Sense of control as a mediator of the leadership-anxiety relationship.

ship between leadership level and anxiety $(\beta=-0.23, P=0.03)$ was significantly and completely mediated by sense of control (95\% CI for indirect effect $=-0.52$ to -0.12$)$; higher leadership level predicted greater sense of control $(\beta=0.36, P<0.001)$, which in turn, predicted lower anxiety $(\beta=-0.61, P<0.001)$ (Fig. $3 B)$. After sense of control was taken into account, the relationship between leadership level and anxiety was no longer significant ( $\beta=-0.01, P=0.94)$. For both measures, the mediating role of sense of control remained significant when demographic variables and mood were entered as covariates. Additionally, despite the parallel pattern of results for the two measures of stress, the models were not redundant; for each outcome, there was significant mediation, even when the other outcome was included as a covariate.

To follow up on this primary analysis, we conducted a supplementary analysis to test whether any of the specific indicators of leadership were particularly strongly related to sense of control and stress. We tested separate mediation models for each indicator of leadership level. For number of subordinates, there was significant mediation for both indicators of stress; having more subordinates predicted a greater sense of control, which in turn, predicted less stress (for cortisol, 95\% CI for indirect effect $=-0.19$ to -0.001 ; for anxiety, $95 \% \mathrm{CI}=-0.38$ to -0.02 ). For authority, the same pattern held. Possessing greater authority over subordinates predicted a greater sense of control, which in turn, predicted less stress (for cortisol, 95\% CI $=-0.30$ to -0.02 ; for anxiety, $95 \% \mathrm{CI}=-0.40$ to -0.10$)$. For number of direct reports, however, mediation was nonsignificant (for cortisol, $95 \% \mathrm{CI}=-0.18$ to 0.03 ; for anxiety, $95 \% \mathrm{CI}=-0.32$ to $0.04)$. The lack of significant mediation for number of direct reports seems largely attributable to the fact that managing many people was not associated with a heightened sense of control $(r=$ $0.14, P=0.19)$. In contrast, both having a greater total number of subordinates and having greater authority over those subordinates were associated with a boost in sense of control $(r=0.24, P=0.03$ and $r=0.38, P<0.001$, respectively).

The results of study 2 provide strong support for our hypothesis across two different indicators of stress, one indicator that captures a psychological manifestation of stress (anxiety reports) and one indicator that captures a physiological manifestation of stress (cortisol). These findings extend the findings of study 1 in three ways. First, they show a dose-response relationship between leadership and stress. Leaders do not possess equally low stress levels. Instead, among leaders, lower stress levels go hand in hand with greater rank and power. Second, the findings identify sense of control as a mediator of the relationship between leadership and stress. Third, analyses of specific forms of leadership level revealed that the stress-buffering effects of leadership are not necessarily conferred to those leaders responsible for managing many people but rather, those leaders who occupy a position characterized by many total subordinates and those leaders who feel that they have substantial authority over those subordinates.

\section{General Discussion}

In two studies, we found clear evidence that leadership is associated with lower levels of stress. This relationship emerged when we compared leaders with nonleaders (study 1) and when we looked at variations in status within a group of leaders (study 2). Furthermore, in both cases, the relationship appeared across two distinct manifestations of stress-one physiological (salivary cortisol) and one psychological (anxiety reports). Finally, by showing the mediating role of the psychological sense of control, we delineate a clear pathway by which an increase in one's leadership level might provide stress-buffering benefits.

The current findings also provide insight into the particular forms of leadership that most clearly boost one's sense of control and as a result, buffer against stress. In particular, occupying a position marked by a large number of subordinates and possessing substantial authority over one's subordinates are two aspects of leadership that confer such benefits. That these positions elevate one's psychological experience of control is not surprising; they are likely to be marked by prestige as well as objective power and influence. In contrast, personally managing a large number of people was not associated with a greater sense of control or less stress, perhaps because ascension to a high-ranking position encourages one to delegate the day-to-day management of subordinates to lower-ranking officials. Altogether, these results highlight the importance of distinguishing between total number of subordinates and number of direct reports, and they suggest that the rank-stress relationship within human organizations may be shaped by certain complexities that are not present within nonhuman primate dominance hierarchies.

In the current investigation, we have focused on sense of control, identifying it as a factor that is influenced by leadership status and in turn, shapes stress. It is known, however, that other factors, such as social support and active coping, also play a part in buffering against the negative effects of job strain $(29,30)$. In future research, it will be important to examine whether changes in one's leadership level elicit corresponding changes in these factors and if so, whether these changes have implications for stress and health.

It is important to note that the low stress levels of leaders may both cause and result from leadership. That is, individuals with low stress levels may be particularly well-suited for leadership and as a result, may select into leadership positions. Conversely,

更


leadership roles may confer lower stress because of the psychological resources that they afford.

In both studies, we found no evidence that the leadershipstress relationship depended on the stability of rank. The current studies, however, were not designed to test for this possibility and do not provide ideal samples for such a test given the relatively higher job security of the participants recruited from the Harvard Executive Education program. A definitive conclusion regarding the role of stability (e.g., whether the leadership-stress relationship holds for leaders with a rank that is less secure or leaders working in less stable organizations) must await future research.

These findings build on research regarding social rank in nonhuman primates to provide a clear answer to the question of whether leadership, in humans, is associated with higher or lower levels of physiological and psychological stress. Both the social science and practitioner literatures have assumed that being a leader is highly stressful, but leaders' physiology and psychology show otherwise. Leaders possess a particular psychological resource-a sense of control-that may buffer against stress.

\section{Materials and Methods}

Participants. Participants were recruited from the Boston metropolitan area and one of many executive education programs at Harvard University. This particular executive education program, which is designed primarily for senior-level officials in the public sector, was targeted to bring to our laboratory many middle- to high-level leaders not found in typical community samples. This program recruits individuals with a rank of GS14 or GS15 on the General Schedule ranking for civilians, which translates to 0-5 and 0-6 in military grades (i.e., Lt. Colonel or Colonel in the Army, Marines, and Air Force; Commander or Captain in the Navy or Coast Guard). SI Text has a detailed profile of the types of jobs and organizations represented in the Executive Education program. Community members were recruited from the greater Boston metropolitan area and screened to be similar to those individuals enrolled in the executive education program in terms of age, sex, and ethnicity. Because some community members were leaders and because not all executive education participants were leaders, we categorized participants as leaders or nonleaders based on their response to the question "are you responsible for managing others?" (yes = leader, no = nonleader).

In study 1 ( $n=231), 216$ participants (136 male; $\left.M_{\text {age }}=46.20\right)$ consented to hormone testing and provided samples of sufficient quantity. Among the leaders, the most frequent ethnicities were white $(69.3 \%)$, black $(9.2 \%)$, and other $(9.2 \%)$. Among the nonleaders, the most frequent ethnicities were white $(69.9 \%)$, black $(12.3 \%)$, Hispanic $(6.8 \%)$, and other $(6.8 \%)$. Participants were asked to indicate how they had come to hold their current position. Of those participants who responded $(n=194)$, the majority indicated being selected through a standard job application process (64.4\%), with approximately one-third having been appointed (35.1\%) and a single individual reporting having been elected $(0.5 \%)$. Participants were also asked to indicate the industry or sector in which they worked. For leaders, the most common responses were government $(n=62)$, military $(n=10)$, and defense $(n=10)$. For nonleaders, the following sectors/jobs were listed more than one time: education $(n=8)$, hospitality/services $(n=8)$, government $(n=5)$, technology $(n=4)$, nonprofit $(n=3)$, construction $(n=3)$, military $(n=2)$, finance $(n=2)$, telecommunications $(n=2)$, software $(n=2)$, and aerospace engineering $(n=2)$. A full list of all sectors is in SI Text.

In study 2 ( $n=88$ leaders), 75 leaders ( 59 male; $M_{\text {age }}=47.44$ ) consented to hormone testing and provided saliva samples of sufficient quantity for testing. The most frequent ethnicities were white $(77 \%)$, black $(12.6 \%)$, and Hispanic $(5.7 \%)$. A majority of participants indicated that they obtained their current position by being selected through a standard job application process $(65.5 \%)$. One-third of participants were appointed (33.3\%), and one participant was elected $(1.1 \%)$. The most commonly reported sectors were government $(n=35)$, military $(n=11)$, and defense $(n=8)$. Other sectors listed more than one time were information technology $(n=3)$, education $(n=2)$, finance $(n=2)$, and healthcare $(n=2)$. A full list of all sectors is in SI Text.

Measures. Salivary cortisol. All participants were screened using the following set of questions, which were designed to identify and exclude those individuals who had medical conditions or were taking medications that might have influenced physiological functioning (including cardiovascular and hormonal measures). Participants were asked the following questions, with a yes response triggering exclusion. (i) "Do you currently have a pacemaker?" (ii) "Do you believe you might be pregnant?" (iii) "Have you been doctordiagnosed with a heart murmur or arrhythmia?" (iv) "Have you been doctordiagnosed with hypertension?" ( $v$ ) "Are you currently taking any drugs or medications that might affect your cardiovascular functioning?" (vi) "Are you currently breast-feeding?" Additionally, before the study, participants were sent instructions informing them that, within $1 \mathrm{~h}$ of the study, they should not (i) eat dairy products (e.g., milk, cream, or cheese) or anything containing live bacterial cultures (e.g., yogurt), (ii) consume caffeine or alcohol, (iii) smoke cigarettes, (iv) exercise, or (v) brush their teeth.

Each participant provided a $1.5 \mathrm{~mL}$ saliva sample at $~ 3: 30$ PM (minimizing diurnal variability) through the passive drool method while completing various questionnaires. Samples were stored at $-25^{\circ} \mathrm{C}$, shipped to Salimetrics, and immunoassayed (lower limit of sensitivity $=0.003 \mu \mathrm{g} / \mathrm{dL}$; standard curve range $=0.012-3.0 \mu \mathrm{g} / \mathrm{dL}$; average intraassay coefficient of variation $=3.5 \%$; average interassay coefficient of variation $=5.1 \%$ ). Cortisol values were logtransformed to reduce skewness. In both studies, there was a significant sex difference [study $1: M_{\text {male }}=0.12, S D_{\text {male }}=0.07 \mathrm{vs}$. $M_{\text {female }}=0.09, S D_{\text {female }}=$ $0.06, t(213)=2.92, P<0.01 ;$ study $2: M_{\text {male }}=0.11, S D_{\text {male }}=0.07$ vs. $M_{\text {female }}=$ $0.07, S D_{\text {female }}=0.03, t(73)=2.67, P<0.01$ ]. Because of this difference, we standardized ( $z$-scored) values separately for men and women, and therefore, a positive value indicated a level that was greater than the average score of individuals of the same sex (31). Outliers (values greater than 3 SDs above or below the mean) were excluded from analysis.

Tenure. All participants were asked to indicate how long they had served in their current position. Responses were converted into months. In study 1, of those participants who provided an answer $(n=153)$, the median tenure was $36 \mathrm{mo}(M=67.39$, minimum $=0.5 \mathrm{mo}$, maximum $=324 \mathrm{mo})$. In study 2 , of those participants who provided an answer $(n=59)$, the median tenure was $48 \mathrm{mo}(M=90.75$, minimum $=0.25 \mathrm{mo}$, maximum $=396 \mathrm{mo})$. Before analysis, values were log-transformed to reduce skewness.

Anxiety. We measured anxiety using the 19-item Spielberger (32) Trait Anxiety Inventory ( $\alpha=0.92$ ). Participants read a number of statements (e.g., "I get in a state of tension or turmoil as I think over my recent concerns and interests") and selected a response to indicate how they generally feel ( $1=$ almost never, 2 = sometimes, 3 = often, 4 = almost always).

Leaders vs. nonleaders (study 1). Participants were asked "are you responsible for managing others?" Those participants who answered yes were categorized as leaders [ $n=148 ; 99(67 \%)$ male; $\left.M_{\text {age }}=46.68\right]$. Those participants who answered no were categorized as nonleaders $[n=65 ; 35(54 \%)$ male; $\left.M_{\text {age }}=44.95\right]$.

Leadership level (study 2). We measured three aspects of leadership that indicate greater rank or power. For the first measure [number of subordinates ( $\alpha=0.82)$ ], participants answered the following two questions: "how many people are subordinate to you within your line of management (i.e., direct and indirect reports)?" and "across your career, what is the maximum number of people that have been subordinate to you within your line of

Table 1. Differences between leaders and nonleaders (means and SDs) in key demographic variables, mood, health practices, health conditions, and sleep behavior in study 1

\begin{tabular}{lccc} 
& $\begin{array}{c}\text { Leaders } \\
(n=148)\end{array}$ & $\begin{array}{c}\text { Nonleaders } \\
(n=65)\end{array}$ & $P$ \\
\hline Age & $46.68(7.71)$ & $44.95(11.2)$ & 0.20 \\
Sex (male) & $66.9 \%$ & $53.9 \%$ & 0.07 \\
Ethnicity (white) & $69.3 \%$ & $69.9 \%$ & 0.93 \\
Education & $4.45(0.94)$ & $3.63(1.38)$ & $<0.001$ \\
Income & $5.06(1.59)$ & $3.03(1.72)$ & $<0.001$ \\
State negative affect & $2.18(0.45)$ & $2.24(0.49)$ & 0.38 \\
State positive affect & $1.67(0.49)$ & $1.70(0.52)$ & 0.63 \\
Exercise regularly & $81.6 \%$ & $75.4 \%$ & 0.30 \\
Use tobacco & $10.9 \%$ & $16.9 \%$ & 0.23 \\
Consume caffeine & $95.9 \%$ & $86.2 \%$ & 0.01 \\
Asthma & $3.3 \%$ & $2.7 \%$ & 0.83 \\
Diabetes & $2.0 \%$ & $2.7 \%$ & 0.72 \\
Heart condition & $4.0 \%$ & $0.0 \%$ & 0.09 \\
Neurological disorder & $1.4 \%$ & $0.7 \%$ & 0.60 \\
Median awakening time & $6: 00 \mathrm{AM}$ & $7: 30 \mathrm{AM}$ & $<0.001$ \\
Hours slept & $6.84(1.12)$ & $7.46(0.99)$ & $<0.001$ \\
\hline \multicolumn{2}{l}{ Sample sizes refer to those } & &
\end{tabular}

Sample sizes refer to those participants who consented to hormone testing and provided a saliva sample of sufficient quantity for testing. 
management (i.e., direct and indirect reports)?" For the second measure, [number of direct reports $(\alpha=0.66)$ ], participants answered the following two questions: "how many people do you, yourself, manage?" and "across your career, what is the maximum number of people that you, yourself, have managed?" Before being averaged into the composite measures, all quantitative measures were log-transformed to reduce skewness and standardized (z-scored). Finally, participants reported their authority and autonomy in making decisions about subordinates (authority: $\alpha=0.89$ ) by indicating their agreement with the following statements: "I can punish or reward subordinates;" "I can promote or demote subordinates;" "I am expected to motivate my subordinates;" and "I supervise subordinates and evaluate or correct their work as necessary" (seven-point scales: $1=$ much less than others in my organization, 7 = much more than others in my organization). Although we averaged these three indicators into a single leadership-level composite $(\alpha=0.61)$ for the primary analyses, we also report subsidiary analysis on the separate indicators.

Sense of control (study 2). Participants completed the eight-item Personal Sense of Power scale (33) $(\alpha=0.69)$, which assesses the extent to which individuals experience a sense of control or power in their relationships. Specifically, participants indicated the extent to which they agreed (five-point scales: $1=$ strongly disagree, $5=$ strongly agree) that a series of statements is true of their relationships (e.g., "I can get people to listen to what I say"). Demographics and mood. Participants indicated their level of education $(1=$ high school, 2 = some college, $3=2$-y degree, $4=4$-y degree, $5=$ postgraduate/ professional degree, or other) and family income $(1=\$ 0-\$ 24,999,2=$ $\$ 25,000-\$ 49,999,3=\$ 50,000-\$ 74,999,4=\$ 75,000-\$ 99,999,5=\$ 100,000$ $\$ 149,999,6=\$ 150,000-\$ 249,999,7=\$ 250,000-\$ 499,999,8=\$ 500,000+)$. To account for transient differences in mood experienced while participants were visiting the laboratory (which could produce transient cortisol differences) (34), participants indicated their Positive Affect $(\alpha=0.61)$ and Negative

1. March JG, Weiner SS (2003) Leadership blues. New Dir Community Colleges 123:5-14 2. Lazarus RS, Folkman S (1984) Stress, Appraisal and Coping (Springer, New York).

3. Levinson H (1981) When executives burn out. Harv Bus Rev 59:73-81.

4. Brady JV, Porter RW, Conrad DG, Mason JW (1958) Avoidance behavior and the development of gastroduodenal ulcers. J Exp Anal Behav 1:69-72.

5. Weiss JM (1971) Effects of coping behavior with and without a feedback signal on stress pathology in rats. J Comp Physiol Psychol 77:22-30.

6. Sapolsky RM (2011) Behavior. Sympathy for the CEO. Science 333:293-294.

7. Sapolsky RM (1989) Hypercortisolism among socially subordinate wild baboons orig inates at the CNS level. Arch Gen Psychiatry 46:1047-1051.

8. Sapolsky RM (1995) Social subordinance as a marker of hypercortisolism. Some un expected subtleties. Ann N Y Acad Sci 771:626-639.

9. Sapolsky RM (2005) The influence of social hierarchy on primate health. Science 308 : $648-652$.

10. Tung J, et al. (2012) Social environment is associated with gene regulatory variation in the rhesus macaque immune system. Proc Natl Acad Sci USA 109:6490-6495.

11. Gesquiere LR, et al. (2011) Life at the top: Rank and stress in wild male baboons. Science 333:357-360.

12. Marmot MG, Shipley MJ, Rose G (1984) Inequalities in death-specific explanations of a general pattern? Lancet 1:1003-1006.

13. Lantz PM, et al. (1998) Socioeconomic factors, health behaviors, and mortality: Result from a nationally representative prospective study of US adults. JAMA 279:1703-1708.

14. Cohen $S$, et al. (2006) Socioeconomic status, race, and diurnal cortisol decline in the Coronary Artery Risk Development in Young Adults (CARDIA) Study. Psychosom Med 68:41-50.

15. Dowd JB, et al. (2011) Education and levels of salivary cortisol over the day in US adults. Ann Behav Med 41:13-20.

16. Fast NJ, Gruenfeld DH, Sivanathan N, Galinsky AD (2009) Illusory control: A generative force behind power's far-reaching effects. Psychol Sci 20:502-508.

17. Weiss JM (1968) Effects of coping responses on stress. J Comp Physiol Psychol 65: 251-260.

18. Dickerson SS, Kemeny ME (2004) Acute stressors and cortisol responses: A theoretical integration and synthesis of laboratory research. Psychol Bull 130:355-391.

19. Miller GE, Chen E, Zhou ES (2007) If it goes up, must it come down? Chronic stress and the hypothalamic-pituitary-adrenocortical axis in humans. Psychol Bull 133:25-45.

20. Taylor SE, Kemeny ME, Reed GM, Bower JE, Gruenewald TL (2000) Psychological resources, positive illusions, and health. Am Psychol 55:99-109.

21. Kirschbaum C, et al. (1995) Persistent high cortisol responses to repeated psychological stress in a subpopulation of healthy men. Psychosom Med 57:468-474.
Affect $(\alpha=0.61$ ) during the study using the 10-item short form developed by Kercher (35) of the Positive and Negative Affect Schedule (36) plus the items angry and happy. In study 2, we also included a self-reported measure of subjective SES (37). In this measure, participants chose a rung from each of two ladders labeled 1-10; the first ladder represented their standing in their community, and the second ladder represented their standing in the United States. The two scales were averaged to form a subjective SES composite $(\alpha=0.78)$

Health-related practices and sleep (study 1). To account for variability in cortisol because of health practices and sleep behavior (38), participants indicated whether they exercised at least one time per week, used tobacco products, or drank caffeinated beverages (all yes or no questions) (Table 1). None of these variables correlated significantly with cortisol ( $P$ values $>0.11$ ). Participants also indicated the time that they awoke that morning and the number of hours that they slept the previous night. Leaders awoke earlier and slept less than nonleaders. Sleep duration was unrelated to cortisol $(r=$ $0.07, P=0.28)$. Although awakening time was related to cortisol $(r=0.24$, $P<0.001$ ), when controlling for awakening time, the difference between leaders and nonleaders in cortisol remained statistically significant. Finally, participants indicated whether they suffered from diabetes, asthma, a heart condition, or a neurological disorder. Each of these conditions was very rare in both groups (leaders and nonleaders), never occurring in more than $5 \%$ of participants (Table 1)

ACKNOWLEDGMENTS. We thank the Harvard Decision Science Laboratory, the Center for Public Leadership at Harvard Kennedy School, Mark Edington, Sheldon Cohen, David Rand, and Robert Sapolsky. This research was supported by National Science Foundation Grants PECASE SES-0239637 and SES-0820441 (to J.S.L.).

22. Karasek RA (1979) Job demands, job decision latitude, and mental strain: Implications for job redesign. Adm Sci Q 24:285-308.

23. Shimazu A, de Jonge J, Irimajiri H (2008) Lagged effects of active coping within the demand-control model: A three-wave panel study among Japanese employees. Int $J$ Behav Med 15:44-53.

24. Smith PM, Frank JW, Bondy S, Mustard C (2008) Do changes in job control predict differences in health status? Results from a longitudinal national survey of Canadians. Psychosom Med 70:85-91.

25. McLeod DR, Hoehn-Saric R, Stefan RL (1986) Somatic symptoms of anxiety: Comparison of self-report and physiological measures. Biol Psychiatry 21:301-310.

26. Conrad A, Isaac L, Roth WT (2008) The psychophysiology of generalized anxiety disorder: 1. Pretreatment characteristics. Psychophysiology 45:366-376.

27. Gust DA, Gordon TP, Hambright MK, Wilson ME (1993) Relationship between social factors and pituitary-adrenocortical activity in female rhesus monkeys (Macaca mulatta). Horm Behav 27:318-331.

28. Preacher KJ, Hayes AF (2004) SPSS and SAS procedures for estimating indirect effects in simple mediation models. Behav Res Methods Instrum Comput 36:717-731.

29. Taylor SE (2008) Fostering a supportive environment at work. Psychol Manag J 11: 265-283.

30. Theorell T, Karasek RA (1996) Current issues relating to psychosocial job strain and cardiovascular disease research. J Occup Health Psychol 1:9-26.

31. Mehta PH, Josephs RA (2010) Testosterone and cortisol jointly regulate dominance: Evidence for a dual-hormone hypothesis. Horm Behav 58:898-906.

32. Spielberger CD (1983) Manual for the State-Trait Anxiety Inventory: STAI (Form Y) (Consulting Psychologists Press, Palo Alto, CA)

33. Anderson C, John OP, Keltner D (2012) The personal sense of power. J Pers 80: 313-344.

34. van Eck M, Berkhof H, Nicolson N, Sulon J (1996) The effects of perceived stress, traits, mood states, and stressful daily events on salivary cortisol. Psychosom Med 58: 447-458.

35. Kercher K (1992) Assessing subjective well-being in the old-old. The PANAS as a measure of orthogonal dimensions of positive and negative affect. Res Aging 14:131-168.

36. Watson D, Clark LA, Tellegen A (1988) Development and validation of brief measures of positive and negative affect: The PANAS scales. I Pers Soc Psychol 54:1063-1070.

37. Adler NE, Epel ES, Castellazzo G, Ickovics JR (2000) Relationship of subjective and objective social status with psychological and physiological functioning: Preliminary data in healthy white women. Health Psychol 19:586-592.

38. Vreeburg SA, et al. (2009) Associations between sociodemographic, sampling and health factors and various salivary cortisol indicators in a large sample without psychopathology. Psychoneuroendocrinology 34:1109-1120. 